Revista de Ciencias Sociales - Número 64 (2014) - Páginas 47-65

¿Es la libertad económica un medio para la libertad política? Friedman y las...

\title{
¿ES LA LIBERTAD ECONÓMICA UN MEDIO PARA LA LIBERTAD POLÍTICA? FRIEDMAN Y LAS REGLAS DEL JUEGO
}

\author{
ECONOMIC FREEDOM IS A MEANS \\ FOR POLITICAL FREEDOM? \\ FRIEDMAN AND THE RULES OF THE GAME
}

\author{
PABLO IGNACIO MÉNDEZ ORTIZ* \\ pmendezortiz@gmail.com
}

\section{Resumen}

$\mathrm{Al}$ hacerse cargo de la continua tensión existente entre los valores de la libertad y la igualdad, Milton Friedman defendió categóricamente la idea que la libertad económica es un requisito necesario y previo para alcanzar la libertad política. Este ensayo busca poner a prueba dicha idea desde la filosofía política, sosteniendo que en última instancia, la relación entre estas dos clases de libertad es inversa. Si entendemos a la política como aquello que nos habilita para vivir colectivamente y encontrar soluciones a nuestras diferencias, entonces, importantes consecuencias pueden derivarse para una adecuada comprensión de la libertad humana y del rol que ésta juega al determinar las reglas fundamentales de la convivencia en sociedad.

\footnotetext{
* Abogado. Licenciado en Ciencias Jurídicas, Universidad de Valparaíso. Artículo recibido el 18 de diciembre de 2013 y aceptado para su publicación el 9 de mayo de 2014.
}

Revista de Ciencias Sociales - Número 64 (2014) - Universidad de Valparáíso - ISSN 0716-7725-Valparáiso, Chile 
Pablo Ignacio Méndez Ortiz

\title{
Palabras claves
}

\author{
Milton Friedman, Libertad Económica, Libertad Política
}

\section{Abstract}

By considering the continuous tenseness between freedom and equality, Milton Friedman strongly defended the idea that economic freedom is a prerequisite for political freedom. This essay aims to examine this idea from a political philosophical approach. If we understand politics as something that enables us to live collectively and find solutions to our differences, then relevant consequences can be obtained in order to understand the role of human freedom plays in the regulation of the basic social coexistence.

\section{Keywords}

Milton Friedman, Economic Freedom, Political Freedom.

\author{
"La razón por la que los hombres entran en \\ sociedad es la preservación de su propiedad. Y el \\ fin que se proponen al elegir y autorizar a los \\ miembros de la legislatura es que se hagan leyes \\ y normas que sean como salvaguardas y barreras \\ que protejan las propiedades de todos los \\ miembros de la sociedad..." \\ John LOCKE
}

Segundo Tratado sobre el Gobierno Civil, § 222.

\section{Introducción}

Resulta ampliamente reconocida la idea de que la política tiene en gran parte que ver con los valores de la libertad y la igualdad. De hecho, la propia declaración de independencia norteamericana de 1776 señalaba que: "Sostenemos como verdades evidentes que todos los hombres nacen iguales; que todos son dotados por su creador de ciertos derechos inalienables, entre los cuales están la vida, la libertad y la búsqueda de la felicidad; que para garantizar estos derechos los hombres instituyen gobiernos, que derivan sus justos poderes del consentimiento de sus 
gobernados; que siempre que una forma de gobierno tienda a destruir estos fines, el pueblo tiene derecho a reformarla o abolirla, a reorganizar sus poderes, o a instituir un nuevo gobierno en la forma que a su juicio garantice su seguridad y libertad" . Con una proclama bastante más escueta, nuestra Constitución Política establece que "Las personas nacen libres e iguales en dignidad y derechos" (art. $\left.1^{\circ}\right)$.

Lo cierto es que desde cada uno de sus correspondientes prismas, la filosofía, la ciencia y la práctica política discurren día a día acerca de los grados de libertad e igualdad que son o debiesen ser observados al interior de la sociedad. Estas respuestas terminan, desde luego, fijando con ello lo que fundamentalmente nos debemos entre nosotros en tanto miembros (i.e. ciudadanos) de la misma. En efecto, las diversas opiniones que podamos ofrecer en temas tan diferentes tales como los impuestos, derechos sociales, educación, aborto, pornografía, drogas, entre otros tantos se debe en última instancia a nuestras propias concepciones de la libertad y de la igualdad ${ }^{2}$. Aunque la verdad sea dicha, también resulta bastantemente aceptada la idea de que ambos valores constituyen verdaderas antinomias dentro del debate político, de modo tal que una reconocida preferencia por la igualdad termina por amenazar los niveles de libertad de que es posible gozar en aquella sociedad, y viceversa.

Haciéndose cargo de dicha tensión, Milton Friedman, quien probablemente fuera el economista más relevante del último siglo, sostuvo que: "[u]na sociedad que anteponga a la libertad la igualdad - en el sentido de los resultados - acabará sin una ni otra. (...) Por otra parte, una sociedad que ponga en primer lugar la libertad acabará teniendo, como afortunados subproductos, mayor libertad y mayor igualdad"3. Para lograr en forma adecuada dicha ponderación de valores, la idea

1. Una explicación acerca del sentido político de este pasaje de la Declaración en ATRIA, Fernando: Veinte años después. Neoliberalismo con rostro humano. Catalonia, Santiago, 2013. Págs. 86-87.

2. SWIFT, Adam: Political Philosophy. Polity Press, Cambridge, 2009. Págs. 1-2.

3. FRIEDMAN, Milton: Libertad de Elegir. Ediciones Folio, Barcelona, 1997. Pág. 209. 
friedmaniana de libertad parte de dos supuestos: (i) la libertad en las organizaciones económicas es en sí, una parte de la libertad en términos generales, por lo que la libertad económica es un fin en sí misma, y; (ii) la libertad económica constituye un medio indispensable para la consecución de la libertad política ${ }^{4}$.

En las líneas que siguen, quiero someter a prueba el segundo de estos supuestos. Y lo quiero hacer desde la filosofía política; en particular, desde lo que es posible esperar de la política al interior nuestra sociedad. Si entendemos a la política como aquello que nos habilita para vivir colectivamente y encontrar soluciones a nuestras diferencias, entonces importantes consecuencias pueden derivarse para una adecuada comprensión de la libertad humana y del rol que ésta juega en este contexto. Ello, creo yo, nos permitirá obtener algunas luces sobre la pregunta que le da el título a este trabajo.

Para ello, este trabajo asume la siguiente estructura. A continuación (2), se expondrá el argumento que Friedman para concluir que, en último término, la libertad económica constituye un pilar fundamental para la libertad política y la metáfora de gobierno en su rol de fijador de las reglas del juego de y árbitro al mismo tiempo. En base a ello, (3) intentaré explicar por qué Friedman no logra comprender qué es lo que significa, en último término, que el gobierno deja fijar estas reglas. Muy por el contrario, (4) entiendo que ello se lo debemos fundamentalmente a la libertad política. Finalmente, (5) se argumentará que un compromiso con la libertad nos obliga a realzar el valor de la libertad política dentro de la política, entendida esta como aquello que nos permite vivir en sociedad, pese a nuestras naturales diferencias y desacuerdos.

\section{Friedman y la preeminencia de la libertad económica en el orden social}

En su clásico Camino a la Servidumbre, Hayek sostuvo que una correcta noción de justicia no incluye la redistribución de los recursos

4. FRIEDMAN, Milton: Capitalismo y Libertad. Ediciones RIALP S.A., Madrid, 1966. Pág. 22.

Facultad de Derecho y Ciencias Sociales - Universidad de Valparaíso - Chile 
por parte del Estado. Muy por el contrario, la única distribución moralmente aceptable dentro de una sociedad es aquella que resulte de los libres intercambios de las personas. El papel del mercado en tanto mecanismo de asignación de recursos deviene instrumentalmente relevante en esta ecuación: los derechos de propiedad y el mercado se transforman en algo valioso debido a que gracias a ellos podemos permitirnos una maximización de la utilidad. Si pudiéramos conseguir dicho objetivo mediante otras formas de asignación, bien podríamos olvidarnos de los derechos de propiedad ${ }^{5}$.

En este orden de ideas resulta comprensible la aversión de los libertarios hacia el gobierno. Prácticamente — argumentaba Hayekla capacidad de los gobiernos para controlar nuestras acciones económicas acarrea como corolario, además de una ineficiencia en la producción de bienes, un aumento en su capacidad para suprimir las libertades individuales a manos de un Estado opresor. Ello terminaría en un control estatal sobre incluso los aspectos más cotidianos de nuestras vidas, derivando en una ruta hacia la servidumbre.

Tal como expresa Sandel, el libertarismo se alza sobre la base del rechazo hacia tres tipos de políticas: (i) un rechazo al paternalismo, lo que se manifiesta en una oposición a aquellas normas que protegen a las personas de cualquier daño eventual que puedan hacerse a ellas mismas; (ii) un rechazo a la legislación sobre temas morales, y; (iii) un rechazo a la redistribución de la renta o del patrimonio ${ }^{6}$. Es por esa razón que la única participación aceptable de parte de un gobierno es aquella destinada a la protección del sistema de libres intercambios entre

5. HAYEK, Friedrich Von: Camino de Servidumbre. Alianza Editorial, $5^{\text {a }}$ Edición, Madrid, 2007. De hecho, la historia del hombre conoció en otros tiempos, algunos mecanismos de asignación de recursos que operan en base a otros criterios, tales como a través de las necesidades comprobadas y reconocidas de ciertos agentes (utilizado principalmente en materias de subsidios estatales), el sistema de asignación en base a la suerte, e incluso, el otorgamiento de bienes en base a un status, rango o clase social. Cfr., TARELLO, Giovanni: Cultura jurídica y política del Derecho. Fondo de Cultura Económica, México, 1996. Págs. 191-204.

6. SANDEL, Michael: Justicia: ¿Hacemos lo que debemos? Random House Mondadori S.A., Barcelona, 2011. Págs. 73-74.

Revista de Ciencias Sociales - Número 64 (2014) - Universidad de Valparáíso - ISSN 0716-7725-Valparaíso, Chile 
los miembros de una sociedad. De ahí entonces que la libertad económica sea reconocida como un elemento necesario para preservar nuestras libertades civiles y políticas. Existe, bajo la lupa libertaria, una primacía por parte de la primera con respecto a las segundas.

Mi opinión es que el propio Friedman es consciente del segundo lugar que ocupa la política frente a la economía. Su conocido Capitalismo y Libertad de 1962 principia sentando las bases necesarias para una relación entre libertad, mercado y gobierno que permita maximizar la libertad económica, postulando que el mercado permite obtener una representación proporcional de mejor manera que lo que lo hace el proceso democrático. Al respecto, plantea que "[1]a característica más señalada de la acción tomada por canales políticos es que tiende a requerir o imponer una conformidad sustancial"7. Es decir, la política opera en base a decisiones adoptadas por una mayoría y que resultan impuestas frente a todos, mientras que: "la gran ventaja del mercado es que permite una amplia diversidad. Es, en términos políticos, un sistema de representación proporcional. Todo hombre puede (por así decirlo) votar por el color de corbata que le guste, y obtenerla; no tiene que ver qué color le gusta a la mayoría y someterse a ella, si es que él está en la minoría".

Pero no solo eso. En Friedman, la libertad económica también constituye una garantía para la obtención de la libertad política. " $A l$ hacer que la autoridad política pierda el control de la actividad económica - escribe-, el mercado elimina esta fuente de poder coercitivo. Hace que la fuerza económica actúe de contención del poder político y no de refuerzo". Para ello, la economía genera diversos núcleos de poder, a diferencia de la política, que descansa en uno solo. Dicha diversidad de núcleos permite así romper el círculo homogéneo de poder propio de la política. El ejemplo que entrega Friedman al respecto es el de aquel individuo que en una sociedad libre es capaz de ganarse la vida por sí mismo y que, por tanto, puede defender y hacer propaganda abiertamente por

7. FRIEDMAN, Milton: “Capitalismo...”, ob. cit. Pág. 30.

8. Ídem.

9. Ibíd. Pág. 31.

Facultad de Derecho y Ciencias Sociales - Universidad de Valparaíso - Chile 
un cambio radical en las estructuras sociales, situación que no se da en aquellos regímenes con una libertad económica limitada ${ }^{10}$.

Este esquema de libre mercado la función del gobierno es primordial. En efecto, "la esfera del Estado ha de ser limitada. Su función principal ha de ser el proteger nuestra libertad contra los enemigos de puertas afuera y de puertas adentro, preservar la ley y el orden, hacer cumplir los contratos privados, fomentar los mercados competitivos" ${ }^{11}$. Dicho en pocas palabras, para Friedman "el gobierno es necesario tanto en su función de foro para determinar 'las reglas del juego', como en su función de árbitro para interpretary hacer cumplir las reglas establecidas"12. Nótese aquí como Friedman introduce una distinción interesante entre las funciones que debe cumplir un gobierno respecto a (i) la determinación de las reglas del juego, es decir, todo aquello que estaría compuesto por "la Ley" y; (ii) la función de árbitro, que estaría dada — según Friedman- por las obligaciones de "proteger nuestra libertad", "preservar el orden”, "hacer cumplir los contratos" y "fomentar los mercados competitivos".

10. A estas alturas ya podrían formularse varias críticas al argumento de Friedman.

Una de ellas está dada por el hecho de que él pareciera olvidar el caso de aquellas personas que, dada su escasa condición material (y la consecuencial dificultad para satisfacer sus necesidades básicas), les es más difícil el ejercer su libertad política. Pese a que esta no es la dirección que quiero asumir en este trabajo, uno desde ya podría plantear que alguien que en nuestro país gana el sueldo mínimo tiene pocos incentivos para adquirir información sobre temas políticos y ejercer esta clase de libertad. Sobre la racionalidad detrás de la ignorancia política, SOMIN, Ilya: "Knowledge about ignorance: New directions in the study of political information". En Critical Review, Vol. 18, Nº 1-3, 2006. Págs. 255-278.

11. FRIEDMAN, Milton: “Capitalismo...," ob. cit. Pág. 14. Nótese cómo años más tarde esta misma idea sería adoptada por Robert Nozick en su famoso Anarquía, Estado y Utopía. La conclusión de la teoría de los derechos de Nozick es que "un Estado mínimo, limitado a las estrechas funciones de protección contra la violencia, el robo y el fraude, de cumplimiento de contratos, etcétera, se justifica; que cualquier Estado más amplio violaría el derecho de las personas a ser obligadas a hacer ciertas cosas y, por tanto, no se justifica; que el Estado mínimo es inspirador, así como correcto". (NOZICK, Robert: Anarquía, Estado y Utopía. Fondo de Cultura Económica, Buenos Aires, 1988. Pág. 7).

12. FRIEDMAN, Milton: “Capitalismo..., ob. cit., Pág. 30.

Revista de Ciencias Sociales - Número 64 (2014) - Universidad de Valparaíso - ISSN 0716-7725-Valparaíso, Chile 
Hasta ahora el argumento friedmaniano consiste en lo siguiente: La libertad económica constituiría un prerrequisito de la libertad política, y por lo mismo, el gobierno debe detentar facultades limitadas que digan relación con la determinación de las reglas del juego, las que deben tender en todo momento al aseguramiento y respeto de la libertad económica. En adición a ello, el Estado debe actuar como árbitro para cumplir las reglas establecidas.

El problema, sin embargo, se nos presenta cuando miramos por nuestra ventana y nos percatamos que en realidad, no es raro encontrarnos con que pasan a formar parte de las reglas del juego ciertas políticas que se alejan del ideal propuesto por Friedman. De pronto nos encontramos notificados de la aparición de un nuevo bono ("bodas de oro", "marzo" o "invierno", según la época del año en que nos encontremos), de la imposición de un nuevo impuesto sobre alguna clase de bien o servicio, o incluso, la instauración de algún permiso administrativo para ejecutar alguna actividad determinada que antes no lo requería, por solo mencionar algunos. Ello nos deja un sabor distinto, pues la realidad se nos presenta como distinta a la promesa libertaria de Friedman.

Lo dicho hasta ahora nos permite rescatar un par de conclusiones. En primer lugar, si observamos con detalle, nada impide que pasen a formar parte de las reglas del juego otras reglas que se alejen de los ideales propuestos por Friedman. Es lo que ocurre, por ejemplo, en todos los casos anteriores. Y ello es así, porque, en segundo lugar, las reglas del juego no aparecen mágicamente de un día para otro. Pese a que Friedman encarga al gobierno una función de determinar las reglas del juego, pareciera olvidar que dichas reglas son el resultado de cursos de acción colectiva (o política, si se prefiere) decididos por una sociedad en su conjunto en un momento y espacio determinados.

\section{Ideas, instituciones y reglas del juego}

Uno de los objetivos principales de la obra de Friedman es el demostrar que existen buenas razones filosóficas y prácticas para asumir un compromiso con el mercado libre. "Mientras se mantenga la libertad efectiva de intercambio, la característica central de la actividad económica

Facultad de Derecho y Ciencias Sociales - Universidad de Valparaíso - Chile 
con la organización de mercado, es que impide que (en la mayoría de las actividades) las personas interfieran unas con otras" ${ }^{13}$. Desde luego, la fascinación de Friedman con la sociedad libre se entiende en el contexto de una lucha intelectual en contra de los totalitarismos socialistas del Siglo XX. Sin embargo, pareciera que el interés de Friedman por demostrar los beneficios empíricos del libre mercado le hace pasar por alto las implicancias que se derivan del hecho que cualquier organización de mercado dependa en último término de una estructura de normas jurídicas (u "ordenamiento jurídico", si se prefiere) adoptada por la sociedad.

En efecto, si hoy en día soy libre para vender (y transferir el dominio de) mi casa, lo soy porque dentro de nuestro ordenamiento jurídico no existe una prohibición general que me lo impida. La verdad sea dicha, lo único que existen son normas que establecen requisitos formales que deben observarse para lograr de manera eficaz dicho objetivo (i.e., que la compraventa se celebre por escritura pública según el art. 1801 del Código Civil, que dicha escritura sea posteriormente inscrita en el Conservador de Bienes Raíces, etc.). Pero nada impide que el día de mañana se inicie una reforma legislativa que proponga, por ejemplo, una prohibición absoluta para vender bienes raíces, o que establezca la necesidad de contar con autorización judicial o de algún organismo administrativo, por ejemplo ${ }^{14}$.

Ello es así debido a que las normas jurídicas tienden a cumplir determinadas funciones. Y con ellas, la sociedad busca la obtención de ciertos fines ${ }^{15}$. Sobre esto, es un lugar común sostener hoy en día que

13. Ibíd.

14. Un ejemplo anecdótico se encuentra en el caso del Código Civil Cubano, que en su artículo 67 que regula los casos de nulidad de los actos jurídicos, establece que "Son nulos los actos jurídicos realizados: a) En contra de los intereses de la sociedad o del Estado". Debiera entenderse, por tanto, que cualquier compraventa celebrada en contra de estos intereses adolecerá de un vicio de nulidad. No hay que ir más allá para concluir que son los jueces los llamados a interpretar esta ambigua norma, caso a caso. Un hecho interesante en un país con abiertas restricciones de garantías constitucionales.

15. Sobre la distinción entre los fines y las funciones del Derecho, SQUELLA, Agustín: Introducción al Derecho. Legal Publishing, Santiago, 2014. Págs. 611697, en especial, Págs. 619 y ss.

Revista de Ciencias Sociales - Número 64 (2014) - Universidad de Valparáíso - ISSN 0716-7725-Valparáiso, Chile 
un ordenamiento jurídico tiene dentro de sus funciones la de distribuir bienes, derechos y cargas entre los miembros de una sociedad, a través de la constitución política y de las principales disposiciones económicas y sociales (aquello que Rawls llamó "la estructura básica de la sociedad") ${ }^{16}$. Ello no es sino una de las tantas manifestaciones que derivan del carácter preferentemente público del Derecho en tanto construcción social. En esta dirección, se afirma, las normas jurídicas — comenzando por la misma Constitución y pasando por las principales leyes que regulan el orden socioeconómico- son las encargadas de establecer qué es lo que nos corresponde y qué es lo que nos debemos unos a otros dentro del marco de la convivencia social ${ }^{17}$.

Por cierto, uno podría discutir acerca de cuál es el valor que en última instancia debe informar dicha distribución de beneficios y cargas entre los miembros de la sociedad. Así, uno podría plantear que aquello debe quedar resuelto mediante una aspiración a la igualdad material (como dirían los socialistas), la maximización de la felicidad (como sostendría un utilitarista), una libertad que garantice los intercambios espontáneos y voluntarios (como plantearía un libertario), ciertos principios de justicia (como diría Rawls), o el bien común (como diría el comunitarismo), entre tantos otros valores. Pero más allá de lo que podamos sentarnos a discutir, lo que resulta cierto a todas luces es que la estructura jurídica (o "las reglas del juego", si optamos por la etiqueta ofrecida por Friedman) constituye en último término el resultado de cursos de acción política ejercidos por diversos órganos del Estado.

Friedman pareciera detectar ello — al menos en un examen prima facie - cuando señala que: "Igual que en un partido hace falta que los jugadores acepten tanto las reglas como al árbitro que las impone, de la misma forma una buena sociedad hace falta que sus miembros estén de acuerdo en las condiciones generales que van a regir las relaciones entre ellos, en los medios para juzgar las diferentes interpretaciones de estas

16. RAWLS, John: Teoría de la Justicia. Fondo de Cultura Económica, México, 2006. Págs. 20-24.

17. Cfr., BARROS, Enrique: “Lo público y lo privado en el Derecho”. En Estudios Públicos, Centro de Estudios Públicos, No 81, 2001. Págs. 5-37.

Facultad de Derecho y Ciencias Sociales - Universidad de Valparaíso - Chile 
condiciones y en algún instrumento para imponer el cumplimiento de las reglas generales aceptadas" 18 .

Pero asimismo pareciera que Friedman no toma conciencia de lo que implica que los miembros de las sociedad deban estar "de acuerdo en las condiciones generales que van a regir las relaciones entre ellos". Una cosa es la libertad dentro del juego (es decir, la libertad económica) y otra muy distinta, la libertad para fijar las mismas reglas del juego (esto es, la libertad política). La libertad dentro del juego depende de las reglas que al efecto han fijado las partes. Ello es así, pues las ideas se encarnan solo cuando se adquieren una forma institucional. De ahí que una idea o propuesta que no se plasme en una política pública solo queda como una declaración de buenas intenciones. En este sentido, solo con instituciones bien diseñadas, esta generación puede hacerse cargo en forma virtuosa de que la próxima viva en una sociedad más justa, sensible y abundante. Las ideas sirven de comburente, pero requieren imperativamente del derecho para transformarse en conductas institucionales ${ }^{19}$.

Si la existencia de un mercado es el resultado de la fijación de ciertas ideas que se han materializado en políticas públicas (o en "reglas del juego" parafraseando a Friedman), y éstas, a su vez, son el resultado de una acción política desarrollada al interior de una sociedad, entonces podemos concluir plausiblemente que la libertad política se traduce como supuesto y mecanismo necesario para la obtención de una libertad económica. Incluso más, existen buenas razones para creer que incluso la libertad política se alza como necesaria para permitirnos, a cada uno de nosotros, defender nuestra propia concepción de lo económico dentro de la sociedad.

\section{El valor de lo político en las reglas del juego}

Reflexionando sobre lo político, el poder y el antagonismo, Chantal Mouffe ha recalcado las dos raíces comunes que tiene lo político,

\footnotetext{
18. FRIEDMAN, Milton: “Capitalismo...”, ob. cit. Pág. 42.

19. BARROS, Enrique: "El derecho como forma de la política y de la sociedad". En Estudios Públicos, Centro de Estudios Públicos, No 130, 2013. Págs. 153173, en especial, Págs. 164-165.
} 
cuestión que puede ser interesante recordar en estas líneas. De un parte, lo político evoca a la polis, es decir, el "vivir conjuntamente" por parte del nosotros político; y por la otra, al polemos, que hace mención a los conflictos que se generan dentro de la propia comunidad política ${ }^{20}$. Estas ideas se encuentran sintetizadas en la escueta pero potente proclama con la que Jeremy Waldron abre su conocido Law and Disagreement: "There are many of us and we disagree about justice" ("Somos muchos y estamos en desacuerdo acerca de lo justo") ${ }^{21}$. La política, en consecuencia, parte de la base que existen desacuerdos profundos y generalizados entre los ciudadanos que forman parte de una misma sociedad, pero que a su vez sienten una necesidad de actuar colectivamente. Esto es lo que Waldron denomina "las circunstancias de la política"22.

A estas alturas, la analogía de Friedman a un juego con un árbitro ha alcanzado un sabor extraño. Porque claro, éste nos presenta a la libertad como aquella que permite a los jugadores decidir su próxima jugada dentro de la cancha, e incluso más, nos indica que es esta libertad la que nos permite, en definitiva, maximizar (utilizando el lenguaje de los economistas) la libertad necesaria que nos permitirá discrepar de las reglas del juego. Pero ¿y la libertad para decidir las reglas del juego e incluso, para decidir si participar o no del mismo? Si la existencia de una sociedad conlleva necesariamente al surgimiento de diferencias radicales entre sus miembros y dichas diferencias se traducen en un orden social determinado, entonces, ¿dónde queda la capacidad de dichos miembros para determinar las reglas fundamentales de aquel orden?

20. MOUFFE, Chantal: El Retorno de lo Político, Ediciones Paidós, Barcelona, 1999. Pág. 14.

21. WALDRON, Jeremy: Law and Disagreement, Oxford University Press, 1999. Pág. 1.

22. Ibíd, págs. 101 y ss. En efecto, Waldron señala que "We may say (...) that the felt need among the members of a certain group for a common framework or decision or course of action on some matter, even in the face of disagreement about what that framework, decision or action should be, are the circumstances of politics". (Pág. 102).

Facultad de Derecho y Ciencias Sociales - Universidad de Valparaíso - Chile 
Rawls, en la introducción a su Liberalismo Político, identificó este problema con la siguiente pregunta: “¿Cómo es posible que pueda existir a lo largo del tiempo una sociedad estable y justa de ciudadanos libres e iguales pero profundamente divididos por 'razonables' doctrinas religiosas, filosóficas y morales?"’3. Y aquí es precisamente donde la política asume un rol olvidado en la teoría friedmaniana.

Podemos aceptar que el diseño de las reglas del juego es lo que, a la postre, termina por aumentar nuestra libertad económica. De ello no cabe duda. Por lo mismo, nadie que entre nosotros plantee la idea de que en nuestro país rige una economía centralizada podría ser tomado realmente en serio. Y ello es así, por cuanto existe todo un catálogo de garantías (lo que los abogados denominan el "Orden Público Económico") tendiente a una libertad de mercado y asegurar la libertad económica ${ }^{24}$. Pero con la misma fuerza que reconocemos ello, debemos también aceptar que el diseño de las reglas forma parte de lo político en el segundo sentido que hemos visto.

La libertad debe imperativamente incluir el derecho a definir las reglas del juego. De lo contrario, no hay libertad. Tan cierto es lo anterior, que el propio Friedman reconoce que la Italia fascista y la Alemania nazista eran regímenes económicos amparados por la libertad de empresa pero que a su vez, carecían de organizaciones políticas libres en la misma sociedad ${ }^{25}$. En otras palabras, pese a existir una libertad económica institucionalizada en estas sociedades, las reglas del juego habían sido impuestas y no decididas libremente por sus ciudadanos a

23. RAWLS, John: Liberalismo Político. Fondo de Cultura Económica, México, 2006. Pág. 18.

24. Cfr., FERMANDOIS, Arturo: Derecho Constitucional Económico. Tomo I. Edic. Universidad Católica de Chile, Santiago, 2ª edición, 2006. Pág. 72, quien define el Orden Público Económico como "el adecuado modo de relación de todos los elementos de naturaleza económica presentes en la sociedad, que permita a todos los agentes económicos, en la mayor medida posible y en un marco subsidiario, el disfrute de sus garantías constitucionales de naturaleza económica de forma de contribuir al bien común y a la plena realización de la persona humana".

25. FRIEDMAN, Milton: “Capitalismo...”, ob. cit. Pág. 24.

Revista de Ciencias Sociales - Número 64 (2014) - Universidad de Valparáíso - ISSN 0716-7725-Valparaíso, Chile 
través de los procesos políticos correspondientes. Y en otros casos, muy por el contrario, existen países que reconocidamente cuentan con un Estado de Bienestar y que a su vez cuentan con un respeto irrestricto en los derechos civiles y políticos (por ejemplo, Suecia). A estas alturas, la defensa que Friedman hace del libre mercado deviene en lo que Kymlicka llama una defensa "contingente", que se encuentra inspirada por un instrumentalismo más que por un respeto irrestricto de la propiedad $^{26}$. Y es precisamente ese el principal talón de Aquiles en la teoría de Friedman: el eslabón pretendidamente más fuerte en la argumentación pasa a ser el más débil.

De ahí entonces el rol de la libertad política dentro de una sociedad. Ella se alza como necesaria para defender nuestras concepciones de lo público dentro de la comunidad política. O, parafraseando a Friedman, la libertad política se reconoce como fundamental para defender las reglas del juego. Sin esta libertad, nada impide que un día cualquiera se levante un tirano, coloque a la polis tras el manto de las sombras y termine por fijar unilateralmente dichas reglas incluso promoviendo la libertad económica. Ello, según hemos visto, no será más que un mero espejismo de libertad ${ }^{27}$.

Pues bien, sea que consideremos a la democracia como un procedimiento para hacer valer nuestros intereses privados en lo público (con Schumpeter o Hayek) o como un consenso moral (con Rawls), necesitamos de un mínimo grado de libertad para participar en la vida política y proponer nuestras propias concepciones acerca de qué es lo que nos corresponde y qué es lo que nos debemos unos a otros dentro del marco de la convivencia social. Sin libertad política, entonces, el jaque mate nos espera a la vuelta de la esquina.

26. KYMLICKA, Will: Filosofía Política Contemporánea. Una introducción. Editorial Ariel, Barcelona, 1995. Págs. 109-110.

27. De hecho, como lo explica ATRIA, Fernando: "El derecho y la contingencia de lo político". En $D O X A, \mathrm{~N}^{\circ} 26,2004$, existen buenas razones para creer que

el colapso de 1973 "se debió a que una buena cantidad de chilenos creyeron que la supervivencia de la comunidad política chilena tenía menos valor que la justicia o injusticia intrínseca de esa práctica”. (Pág. 342).

Facultad de Derecho y Ciencias Sociales - Universidad de Valparaíso - Chile 
¿Es la libertad económica un medio para la libertad política? Friedman y las...

\section{Conclusión: no todo lo que brilla es oro}

Pero no todo está perdido. De hecho, no es mi intención ser trágico en estas líneas. Según hemos visto, Friedman señaló enfáticamente que una sociedad fundada en la libertad no proporcionaría igualdad, aunque probablemente (como un subproducto) los niveles de ésta serían mayores que en otros sistemas alternativos. Y para ello, entendió que la libertad económica constituye un fin en sí mismo, que a su turno constituye un medio indispensable (aunque no suficiente) para el respeto de la libertad política. Sin embargo, pareciera que la pasión de Friedman por combatir los sistemas igualitarios (i.e., socialistas) y demostrar las ventajas del libre mercado, le hacen pasar por alto el valor que tiene la libertad política en cuanto mecanismo para resguardar la libertad en general.

Nosotros no estamos obligados a recorrer el mismo camino. Bien podemos reafirmar nuestro compromiso con la libertad humana como Friedman lo hizo, y al mismo tiempo concederle a la política el rol que se merece. Según hemos visto, la libertad política se alza como necesaria para defender nuestras propias concepciones de lo económico dentro de una sociedad determinada. No basta con gozar de libertad para realizar nuestra próxima jugada dentro del juego, sino que además, requerimos de libertad para proponer y defender las que según nosotros estimemos son las mejores reglas del juego. Tener presente lo anterior deviene particularmente relevante en momentos como este, en que el debate público se encuentra dirigido hacia temas no pacíficos y que requieren necesariamente de un gran consenso social.

Así, hemos sido testigos de cómo se ha vuelto frecuente que en nombre de la libertad o de la igualdad se ponga en evidencia el rol suficiente o insuficiente del Estado en materia de educación; se discutan las acciones estatales que deben adoptarse con respecto al aseguramiento de la salud; se critique constantemente la institucionalidad asociada al medio ambiente, libre competencia, derechos de los consumidores y mercados complejos (i.e, productos farmacéuticos, mercados de capitales, regulación de servicios públicos, entre otros). En fin, nos encontramos en un momento en que el mercado en tanto mecanismo de asignación de recursos se encuentra constantemente cuestionado debido a la desigualdad y a la tendencia corrosiva que genera ${ }^{28}$.

28. Las etiquetas son de SANDEL, Michael: Lo que el dinero no puede comprar. Los límites morales del mercado. Random House Mondadori S.A., Barcelona,

Revista de Ciencias Sociales - Número 64 (2014) - Universidad de Valparáíso - ISSN 0716-7725-Valparaíso, Chile 
Incluso, vale la pena recordar al respecto las constantes demandas de algunos sectores por una asamblea constituyente que tenga por finalidad la configuración de una nueva carta fundamental que reemplace a la Constitución Política de 1980.

Nuestra Corte Suprema también ha tenido mucho que decir en estos temas. La práctica indica que durante el último tiempo, nuestro máximo tribunal ha tomado un papel activo en diversas áreas del Derecho, mostrando un compromiso con los ciudadanos en general. Es cuestión de observar la reciente labor y posición que ha adoptado, por ejemplo, en materia de libre competencia (a propósito del fallo sobre la colusión de farmacias $)^{29}$; sobre el aumento unilateral de los planes de salud por parte de las Instituciones de Salud Previsional o ISAPRES ${ }^{30}$; con respecto a la protección de los consumidores ${ }^{31}$; o incluso en materia

2013. Págs. 13-14, quien a propósito señala, de una parte, que en una sociedad en la que todo está en venta, la vida resulta más difícil para quienes menos tienen. Por tanto, mientras más cosas puede comprar el dinero, mayor relevancia adquiere la abundancia económica (lo cual genera un efecto discriminador). Pero por la otra, el mercado también tiene la aptitud para corromper (i.e. mercantilizar) ciertas actitudes, bienes o tendencias. En efecto, pagar a nuestro hijo para que lea el libro asignado en el colegio podrá ser una medida con cierto grado de éxito, aunque con ello le enseñe al mismo tiempo que la lectura es una tarea en lugar de una fuente de satisfacción en sí.

29. C.S., Rol 2.578-2012, Sentencia del 07 de septiembre de 2012. Nótese como incluso la Corte Suprema introduce ciertas calificaciones valorativas o juicios de valor, estimando por ejemplo, que la colusión de las infractoras dejó en evidencia que en este caso "El interés económico se sobrepuso a la dignidad humana, a la vida y a la salud de las personas..." (Considerando $90^{\circ}$ ).

30. La jurisprudencia de la Corte Suprema en este sentido es vasta y públicamente conocida. A modo meramente ejemplar, pueden verse los Roles 8327-2012 y 8478-2012, ambas con sentencias del 07 de enero de 2013.

31. Por ejemplo, C.S., Rol 12.355-2011, Sentencia de 24 de abril de 2013, que en su sentencia de reemplazo acogió la "acción colectiva" en contra de Cencosud por cobros en exceso con motivo de un aumento unilateral de la comisión de mantención de tarjetas y ordenar la eliminación de cláusulas contractuales abusivas. En el mismo sentido, C.S., Rol 12.553-2011, Sentencia de 30 de abril de 2013, que condenó a tres de los ejecutivos de Eurolatina como autores de los delitos de usura y estafa.

Facultad de Derecho y Ciencias Sociales - Universidad de Valparaíso - Chile 
ambiental a propósito de la calificación de proyectos de inversión al interior Sistema de Evaluación de Impacto Ambiental ${ }^{32}$. Sea cual sea la calificación que se le dé a la jurisprudencia más reciente de la Corte Suprema ("activismo judicial", "compromiso con los derechos de los ciudadanos", etc.), pareciera que la situación descrita se debe a algo más que a la simple integración de los derechos fundamentales con la teoría del Derecho y el procedimiento administrativo.

Mientras tanto, entre nosotros la discusión sobre todos estos temas recién está comenzando.

Por lo mismo, cualquiera sea la opinión que uno tenga en cada uno de ellos, vale la pena tomar desde ya conciencia que tan importante es participar dentro del juego, como lo es el poder decidir cuáles serán las próximas reglas del mismo. Así como utilizamos la expresión "no todo lo que brilla es oro" para dar cuenta de que algo correcto o bueno puede tener en el fondo algo de malo, la libertad económica no constituye el último valor a tener en cuenta para la vida en sociedad, pues graves consecuencias para la política pueden derivarse de ello. En la medida que tengamos presente ello, podremos defender el real valor de la libertad y su rol que juega ésta en la vida en la política, entendida esta como aquello que nos permite en último término estar juntos y vivir en aquella sociedad.

32. Existe una abundante jurisprudencia de la Tercera Sala de la Corte Suprema en esta materia. Para un panorama general y una identificación de las más importantes sentencias, cfr. CORDERO, Luis: "Estudio Preliminar. Corte Suprema y Medio Ambiente: ¿Por qué la Corte está revolucionando la regulación ambiental”. En Cordero, Luis (coord.): Jurisprudencia Ambiental. Casos Destacados. Tomo I, Legal Publishing, Santiago, 2012. Págs. 3-24.

Revista de Ciencias Sociales - Número 64 (2014) - Universidad de Valparáíso - ISSN 0716-7725-Valparaíso, Chile 


\section{BIBLIOGRAFÍA}

ATRIA, Fernando: "El derecho y la contingencia de lo político". En DOXA, No 26, 2004, pp. 319-345.

__ "Sobre la soberanía y lo político". En Derecho y Humanidades, Universidad de Chile, No 12, 2006, pp. 47-93.

_- Veinte años después. Neoliberalismo con rostro humano. Catalonia, Santiago, 2013.

BARROS, Enrique: "Lo público y lo privado en el Derecho". En Estudios Públicos, Centro de Estudios Públicos, No 81, 2001, pp. 5-37.

__ "El derecho como forma de la política y de la sociedad". En Estudios Públicos, Centro de Estudios Públicos, No 130, 2013, pp. 153-173.

CORDERO, Luis: "Estudio Preliminar. Corte Suprema y Medio Ambiente: ¿Por qué la Corte está revolucionando la regulación ambiental". En Cordero, Luis (coord.): Jurisprudencia Ambiental. Casos Destacados. Tomo I, Legal Publishing, Santiago, 2012, pp. 3-24.

FERMANDOIS, Arturo: Derecho Constitucional Económico. Tomo I. Edic. Universidad Católica de Chile, Santiago, 2ª edición, 2006.

FRIEDMAN, Milton: Capitalismo y Libertad. Ediciones RIALP S.A., Madrid, 1966.

Libertad de Elegir. Ediciones Folio, Barcelona, 1997.

HAYEK, Friedrich Von: Camino de Servidumbre. Alianza Editorial, $5^{\mathrm{a}}$ Edición, Madrid, 2007.

SOMIN, Ilya: "Knowledge about ignorance: New directions in the study of political information". En Critical Review, Vol. 18,

$\mathrm{N}^{\text {os }}$ 1-3, 2006, pp. 255-278.

KYMLICKA, Will: Filosofía Politica Contemporánea. Una introducción. Editorial Ariel, Barcelona, 1995.

MOUfFE, Chantal: El Retorno de lo Político. Ediciones Paidós, Barcelona, 1999.

NOZICK, Robert: Anarquía, Estado y Utopía. Fondo de Cultura Económica, Buenos Aires, 1988.

RAWLS, John: Teoría de la Justicia. Fondo de Cultura Económica, México, 2006.

__ Liberalismo Político. Fondo de Cultura Económica, México, 2006.

Facultad de Derecho y Ciencias Sociales - Universidad de Valparaíso - Chile 
¿Es la libertad económica un medio para la libertad política? Friedman y las...

SANDEL, Michael: Justicia: ¿Hacemos lo que debemos? Random House Mondadori S.A., Barcelona, 2011.

- Lo que el dinero no puede comprar. Los límites morales del mercado. Random House Mondadori S.A., Barcelona, 2013.

SQUELLA, Agustín: Introducción al Derecho. Legal Publishing, Santiago, 2014.

SWIFT, Adam: Political Philosophy. Polity Press, Cambridge, 2009.

TARELLO, Giovanni: Cultura jurídica y política del Derecho. Fondo de Cultura Económica, México, 1995.

WALDRON, Jeremy: Law and Disagreement. Oxford University Press, 1999. 